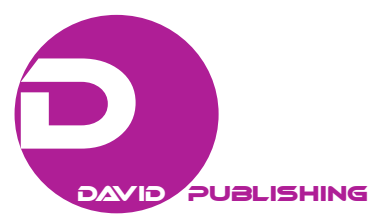

\title{
Existence and Essence in Mulla Sadra’s Ontology
}

\author{
Muhammad Kamal \\ The University of Melbourne, Victoria, Australia
}

\begin{abstract}
This paper examines the relationship between existence and essence in Mulla Sadra's ontology. It analyses his arguments against the possibility of a real distinction between existence and essence of the existing entities in the world, which is advocated by Ibn Sina, and then explicates how Mulla Sadra after rejecting Ibn Sina’s notion of the real distinction interprets the ontological difference between reality and the possible world by reflecting on his doctrines of the principality of existence (asālat al-wujū ) and the gradation of the reality of existence (tashkik al-wujūd), rather than existence-essence dichotomy.
\end{abstract}

Keywords: ontology, existence, essence, accidentality of existence, unity, multiplicity

\section{Introduction}

Perhaps the most prominent doctrine in Mulla Sadra's philosophy is that of the principality of "existence". ${ }^{1}$ This doctrine is a clear departure from another metaphysical position of Suhrawardi's essentialism and Muslim Aristotelian Neo-Platonist thinkers, such as Ibn Sina (980-1037). Contrary to Suhrawardi (1154-1191), Mulla Sadra rejects the idea of the non-reality of existence and this rejection, as described by him, is the outcome of a mystical experience or a spiritual journey from the dark abode of illusion to the vision of the truth. Mulla Sadra's ontology, henceforth, can be rightly understood in opposition to Suhrawardi's metaphysical position, in which the principality of essence has become its salient feature. For Suhrawardi, "essence", rather than "existence", is what makes something to be and constitutes its nature. The essence of a tree, for example, makes it to be a tree, while "existence" remains conceptual and unreal (Suhrawardi, 1999). Since existence has no concrete reality and an entity is known through its essence, then in this metaphysical position, there would be no real distinction between essence and existence, because existence is unreal.

The idea of the principality of existence is peculiar to Mulla Sadra's metaphysics, even though, Ibn Sina, before Mulla Sadra, conceived of God as pure existence and the metaphysical foundation of the possible world. In Kitāb al-Shifā, Ibn Sina describes this metaphysical foundation as pure existence to safeguard the reality and simplicity of God as the first principle,

The existence of the Necessary Existent cannot at all be a composite, [deriving] from multiplicity. The true nature of the Necessary Existent can in no manner be shared by another. From our verifying [all] this, it follows necessarily that the

Muhammad Kamal, Dr., Asia Institute, The University of Melbourne, Victoria, Australia.

1 Mulla Sadra, whose full name is Mulla Sadr al-Din Muhammad Ibrahim Shirazi, a post-Ibn Sinan Muslim philosopher (1572-1640), lived during the Safavid period in Iran. His intellectual life began in Isfahan where he studied philosophy and religious sciences and was a follower of Suhrawardi's essentialism. Later, he changed his philosophical conviction from the principality of essence to the principality of existence. His philosophical ideas conflicted with the belief system of the religious elite in Isfahan and he was forced into self-exile. He left Isfahan for Kahak, a village near the city of Qum where he lived quietly for many years, wrote his major philosophical works and developed his new ontology. 
Necessary Existent is not [dependent on] relation, is neither changing nor multiple, and has nothing associated with His existence that is proper to Himself. (Sina, 2005, p. 30) ${ }^{2}$

For if God were composite and not simple, then God would not be the first cause and His existence would presuppose its components. It is also not possible to define God as pure essence. Essence does not exist by itself and relies on existence to be actual. Consequently, if Go were defined as pure essence, then He would not exist. The concrete reality of essence is ontologically dependent on existence. We better understand this point when we explain how Ibn Sina interprets the existence of a possible being and distinguishes them from God. A possible being does not exist by itself. It is brought into existence by something other than itself. Its existence is caused and happened to it or added to its essence to make it real in the world, "The rest of the things, other than the Necessary Existent, have quiddities. And it is these quiddities that in themselves are possible in existence, existence occurring to them externally" (Sina, 2005, p. 276). Whatever is coming into existence is a possible being and this happens through "adding" existence to its essence from the outside. To say that existence is added to essence is equivalent of saying that essence does not exist in its own right. A possible being's essence is not a concrete reality, but it becomes real when it is actualised by existence, and then existence is bound to be its accident. ${ }^{3}$ The distinction between existence and essence constitutes the nature of all possible beings. The concrete reality of possible beings is determined by this fusion of existence and essence. This distinction necessarily entails the difference between the Necessary Existent (reality) and the possible world. Existence that belongs to a possible being is contingent and temporal. God's existence, by contrast, is necessary and eternal because it is not composite. No doubt, Ibn Sina ratifies the primacy of existence, particularly, in describing God's existence, yet, the distinction between existence and essence in the possible world appears to be real. This distinction has also become a decisive method to differentiate two realms of existence form each other. If the real distinction of existence and essence of the possible beings is denied, then a possible being, like the Necessary Existent, would become simple and not composite. But the denial and acceptance of the real distinction between existence and essence renders problematic, and Mulla Sadra deals with it in his ontology.

\section{Mulla Sadra's Doctrine of the Principality of Existence}

Mulla Sadra's ontology is rightly understood as an opponent of Suhrawardi's doctrine of the principality of essence and Ibn Sina's real distinction between essence and existence in the possible world. At the beginning of his philosophical career, Mulla Sadra was a proponent of Suhrawardi's metaphysics and defended the principality of essence. Later, he changed his philosophical standpoint, and this change, which is characterized by the principality of existence, described in his major philosophical works, is revealed to him in a mystical experience,

As for myself, in the days gone by I was a vigorous defender of the thesis of the principality of quiddities and the conceptuality of $w u j \bar{u} d$, until my Lord guided me and made me see its proof. Then it was unveiled to me with supreme evidence that [the case of the quiddities] was a reverse of what they conceived and decided [concerning this matter]. Glory be to God Who, through the light of veritable understanding, allowed me to leave the darkness of opinion, Who made the

\footnotetext{
${ }^{2}$ Abu Nasr al-Farabi (870-950) introduced the distinction between existence and essence of the possible beings into Muslim philosophy before Ibn Sina. This distinction can also be traced back to Aristotle. But Ibn Sina focused more on this distinction to draw a clear line of demarcation between the Necessary Existent and the possible world, which was also theologically significant. 3 It should be remembered that "accident" in this context is not a logical accident attributed to a primary substance, for example, one of the categories, such as quality, quantity, relation and so on, in Aristotle's logic. Existence is something happens to essence so that it will become real in the world.
} 
clouds of doubt in my heart dissipate through the rising of the Sun of the Truth, and Who established me on the 'firm doctrine' in this life and in the Hereafter. (Sadra, 2014, p. 37; 1999a, pp. 1, 9; 1981, pp. 50-51)

Mulla Sadra's standpoint is not a simple conversion but a crucial philosophical change from the position of essentialism to existentialism with significant ontological consequences. It is a new understanding of reality where existence $(w u j \bar{u} d)$ par excellence becomes an objective reality and the principle of all things. Existence stands out above and exceeds everything. According to Mulla Sadra (2014), this new ontology is imperative for our knowledge and understanding of the world. It is also the most important of all philosophical inquires as its subject matter, namely "existence" is the greatest among all (Sadra, 2014). This greatest subject of philosophical inquiry, at the same time, transcends logical categories. It can neither be defined nor described. Mulla Sadra's views against any possible definition of existence can be summarised in three arguments.

First, in a definition, we disclose the essence or "what-ness" of a defined subject. This is what Aristotle has also confirmed in Metaphysics, stating that a definition identifies the essence of what is defined, “...when we say what it is, we do not say 'white' or 'hot' or 'three cubits long', but 'man' or 'God'” (Aristotle, 1995, p. 15). But existence as the only and simple reality has no essence, and for this reason, it cannot be defined. This argument is reminiscent of what Ibn Sina has already established before on the ground of the non-composite nature of the Necessary Existent.

Second, existence is not an existent to have genus and differentia. For this reason, the Aristotelian rule of definition, in particular "analytical definition", which involves genus and differentia, and then it is not applicable to existence. In al-Mashā'ir, Mulla Sadrawrites that,

It [wujūd] cannot be known through definition because it has no genus and no significant difference. Thus, it has no [logical] definition. It cannot be described either, because it cannot be conceived through anything that is more manifest or better known than it, no through a form that is equal to it. (Sadra, 2014, p. 7; 1999a, pp. 1, 68; 1999b, p. 27)

The uniqueness and unity of existence remain beyond a logical definition. Third, existence is not a universal concept. Conceptualization by the intellect requires correspondence between the concept in thinking and the existence of the conceptualised object outside thinking. Existence, which has no single way of actualisation, is not a thing, for example, a tree to exist and being conceptualized (Sadra, 2014). Consequently, the denial of essence, genus and differentia to existence, and to say that existence is neither a concept no an existent, make it indefinable.

In fact, the idea of indefinability of reality is not attributed to Mulla Sadra's ontology. It can be traced back to Ibn Sina and then Plotinus who believes that the "One" is transcending all predicates including existence, and nothing can be said of it, for whatever is said of the "One", points toward composition. In Enneads, Plotinus clarifies this point by stating that the possible definition of the "One" could be only "the indefinable”, because the "One” is not a thing. This Plotinian view is like Mulla Sadra's view expressed in the first and second arguments against any possible definition of existence (Plotinus, 1991). Ibn Sina who is a neo-Platonist philosopher holds similar views before Mulla Sadra and comments that since the Necessary Existent has no quiddity, no genus and no differentia, it is, then indefinable (Sina, 2005). The question arises here is: How do we know the reality of existence if it is indefinable and transcends all logical categories? For Mulla Sadra, existence has no essence and is without genus and differentia. Besides, it is neither an object of perception nor of rationalistic analysis. If a concept in one way or another represents an external reality and existence is likewise a concept, then it should represent a real existence as a thing outside thinking. But, there is 
nothing outside thinking to represent the concept of existence. Nevertheless, the non-representation of the concept of existence is not the denial of its reality. It is true that existence is neither an existent nor a universal determination to be grasped rationally, but then this epistemological limitation, does not curtail Mulla Sadra's philosophical inquiry into the meaning of existence. He tries to find an adequate cognitive tool to disclose the meaning of existence, and at the same time, this new cognitive tool would be different from perception and reasonas "its inclusion happens in another mode of inclusion, and no one has gnosis of it except the mystics-i.e., those who are firmly grounded in [mystical] knowledge” (Sadra, 2014, p. 9). By relying on the faculties of perception and reason the human mind remains incapable to understand the meaning of existence and existence becomes inaccessible to the human mind. The possibility of knowing existence is dependent of the mystical experience, a gnostic approach rather than a rationalistic discourse.

The principality of existence does not eliminate the question concerning the relationship between existence and essence of entities in the world. It is necessary to understand how Mulla Sadra deals with this distinction; whether he maintains Ibn Sina's metaphysical position, or he goes beyond it. To understand his position we analyse his views in al-Masha 'ir, where he explains that accepting any kind of distinction between existence and essence is beset with the problem of demonstrating this relationship in terms of priority, posteriority, and simultaneity, "If wujūd were to be existent, then either it would be anterior to quiddity or posterior to quiddity, or the two would be simultaneous” (Sadra, 2014, p. 24). Since for Mulla Sadra existence is primary, essence must be either posteriori to existence or they both are concurrent. But an appropriate examination of Mulla Sadra's ontology will demonstrate that the doctrine of the principality of existence does not allow a relationship between essence and existence to be established, simply because a relationship is founded on the concrete reality of both. If we assume that existence and essence are both real, then we must demonstrate priority or posteriority of one of them. In this case, Mulla Sadra's views on the reality of the world remain in the domain of Ibn Sina's metaphysics.

The three assumptions on the relationship between existence and essence postulate the reality of both. For, if one of them is unreal, the relationship between them renders meaningless. However, against the first assumption Mulla Sadra argues that if existence is prior to essence, then the actualisation of existence will be independent of essence. In this case, a qualification of an entity would be prior to a qualified entity and remains independent of it. The second assumption, which pertains to posteriority of existence to essence, would lead to an infinite regression, because it suggests that essence exists before existence or there is an existence of essence before it is coming into existence in the world. In the third assumption, Mulla Sadra (2014) argued that if we think that existence and essence are simultaneous, then we assume that essence is existent at the same time as existence, it exists by itself, not by or in existence. This necessarily follows that essence exists with existence or it derives its existence from somewhere else other than existence. This assumption, therefore, has the same consequence as the previous assumption, and is essentially false because its antecedent is also false (Sadra, 2014). Mulla Sadra (2014) also argued that if there is a real relationship between existence and essence, this relationship should have existence, which is going to have a relation to this relation and so on. This problem of regressio ad infinitum can be solved only when the reality of essence is denied (Sadra, 2014).

After arguing against these assumptions for the sake of validating the principality of existence rather than its priority, Mulla Sadra also criticises Ibn Sina's metaphysical position of accidentality of existence. As we know, Ibn Sina accepts the primacy of existence when he describes the nature of the Necessary Existent, but accepts the distinction between existence and essence in the possible world. His doctrine of accidentality of 
existence points to the possibility of a real distinction and relationship between them. The essence of a possible being becomes actual only when existence is added to it. But Mulla Sadra disagrees with Ibn Sina's interpretation, and proclaims that the priority of existence to essence does not in the least resemble that of cause to effect, or to the priority of the receptacle to the thing received, "It is the priority of the real to the metaphorical” (Sadra, 2014, p. 25). When we think of existence and essence in terms of a causal relationship, and to assert that existence brings about essence into existence, we simply confirm the objective reality of both. This supposition is in a retrieve to Ibn Sina's metaphysical dualism. The notion of accidentality of existence or conceiving of existence as something added to essence has no room in Mulla Sadra's ontology, because to think of essence as something different from existence and vice versa, is polemical and destroys the foundation of his existentialist-monism.

As mentioned before, the essentialist philosophers, like Suhrawardi and his followers, deny the reality of existence, while, by contrast, Mulla Sadra backs the reality of existence. In both philosophical positions the possibility of a real relationship and distinction between existence and essence are rejected, because one of them remains unreal. The doctrine of the principality of existence like that of Suhrawardi does not support any sort of metaphysical dualism. Yet, we still think about essence of the possible beings in the world. This way of thinking about the distinction between essence and existence of entities in the world, according to Mulla Sadra, is inherited from intellectual analysis and not from the ontological structure of the entities in the world. It is embedded in the apprehension of what exists externally. The human mind draws a distinction between existence and essence by perceiving entities in the world and analyse them conceptually, "There is, therefore, no relation between the two except as considered in thought” (Sadra, 2014, p. 27). Mulla Sadra also (2014) stated that

And since you have learned that reality in concreto and the existent in truth is nothing other than existences without the essences, it has been proven that wujū is a simple reality, that it has no genus and no specific difference constituting it, [that it has] no species and no specific difference dividing it, and that it has no particularization. Rather, its particularisation is by its own essence [itself], which is simple. (Sadra, 2014, p. 48)

Here, the dichotomy of existence and essence is described as intellectual and one which exists only in thinking. When we are asked about the quiddity of an existing entity, we analyse it into universal determinations and distinguish them from its existence. For example, we separate the existence of a tree from its universal determinations, such as being green and tall in thinking while describing it. It is through an intellectual analysis that the existence of a tree is distinguished from its essence. Essence is a product of such analysis having no reality of its own. It is dependent of thinking; otherwise, it is permanently concealed in the abyss of nothingness.

Mulla Sadra has no problem with the distinction between existence and essence of the possible beings as long as essence is described as the product of our intellectual analysis, as he remarks that

As for the order in the mind, what is anterior is the quiddity, because it is a universal concept in the mind that is obtained with its very essence in the mind. Therefore, quiddity is the principle in mental judgements and not in the judgments related to the external world. This anteriority is anteriority by meaning and quiddity and not by wujūd. (Sadra, 2014, p. 32)

He expresses similar views in al-Asfär , where the idea of a real distinction between existence and essence is again rejected (Sadra, 1999a). This priority in this respect is a priority in meaning rather than a priority in 
existence. It is also not a priority in terms of causality or temporality because essence is not real and cannot become the cause of existence or precede it in time. Every entity in the world is an individual instance of existence and determined by it (Suárez, 1983). ${ }^{4}$

In the pre-intellectual analysis of an entity in the external world there is no distinction between existence and essence. The rejection of the real distinction between existence and essence was also discussed and developed by Mulla Sadra’s followers. Mulla Hadi Sabzawari (1797-1873), a Sadrian thinker, explained Mulla Sadra's position by identifying two modes of existence; real ('aynī) and mental (dhihn $\bar{l}$ ). Essence, which is conceptual and exists only in thinking, assumes the second mode of existence and furnishes the basis of our intellectual analysis. Hence, the distinction between existence and essence becomes of that between the real existence and the mental existence. An entity has existence in the real world and in thinking when it is conceptualised. The difference between these two modes of existence lies in the way they produce their effects. For example, real water quenches thirst, but the conceptual water does not produce this effect. In addition to this difference, the real existence of an entity becomes a ground for its existence in the intellect. It is the reality of existence and not essence that discloses itself to the intellect at a different level of existence (Sabzawari, 1977).

\section{The Ontological Difference Between Existence and Existents}

We must now proceed to further consideration of the relation of the reality of existence and the existing entities. As we have already stated that for Ibn Sina, the real distinction between existence and essence of possible beings is a criterion for separating these beings from the Necessary Existent. And then the denial of the real distinction between existence and essence is at the same time the denial of the difference between the Necessary Existent and possible beings, because only the Necessary Existent is not composite. How does, then, Mulla Sadra draws the line of demarcation between existence and existents, especially when Ibn Sina's notion of the real distinction between existence and essence of the possible beings is rejected? It is true that Mulla Sadra advocates the reality of existence; nevertheless his ontological position does not abolish the distinction between existence $(w u j \bar{u} \bar{d}$ ) and existents (mawjū $\bar{a} \bar{t}$ ) or between the reality of existence as the ontological ground and the existing entities. But this distinction between them is not founded on existence-essence dichotomy. In Mulla Sadra's ontology, whatever exists is a mode of the reality of existence and is different from existence. The relation between them is seen as that of the ground with the grounded.

Existence, as the sole ontological reality, is the unifying ground of various modes and grades of its own self-manifestation. Every entity exists through the reality of existence and is dependent of it ontologically. Existence is the ontological reality, but it is not an existent, meanwhile, their difference does not exclude unity because an existent is a mode of existence. Existence is the eternal reality and its modes are temporal, which

\footnotetext{
${ }^{4}$ It is worth noting that this discussion on the relationship between existence and essence proved to be a persistent problem in medieval metaphysics in the West. With reference to this discussion Francis Suárez identifies three interpretations: the Thomistic, the Scoteistic, and that of Suárez and some scholastic thinkers. The first interpretation represents the views of Thomas Aquinas and his followers. These thinkers, under the influence of Ibn Sina, advocated the idea of a real distinction between existence and essence of all finite or created beings. In every finite being existence is one thing and essence the other, In the case of all finite beings, unlike the Necessary Existent who is simple, the distinction between existence and essence is real. The second interpretation by John Duns Scotus does not recognise the reality of this distinction. The third interpretation represents views of Suárez and some scholastic thinkers, such as Alexander of Alexandria, Aureolus, Henry of Ghent, Godfrey of Fontaines, Alexander Achillinus and others. For these thinkers, existence and essence of finite beings are not distinct and should not be seen as two real extremes. They appear different only in thinking.
} 
are in constant change. It follows from Mulla Sadra's interpretation, an existent is objective but not a reality and the possibility of all individual existents is due to existence. Existence, which always is, constitutes the reality of all existents. But this ontological difference cannot be apprehended in terms of essence-existence dichotomy in Mulla Sadra's ontology. After rejecting Ibn Sina's notion of the real distinction between existence and essence Mulla Sadra aims at establishing the difference between the reality of existence and existents in terms of internal causality and temporality. The ontological reliance of all existents on existence becomes the foundation for the principle of causation and leads to the rise of two spheres of existence. The latter is causally dependent of the former. If existence ( $w u j \bar{u} d)$ is the only reality, then whatever is other than existence has been brought into being by existence. An existent is an individual instance of the self-manifestation of existence and may or may not exist. By contrast, existence is necessary by itself, and unlike an individual instance of its manifestation, it cannot not be and always is. The ontological difference between existence and its modes is then understood as the distinction between cause and effect. But, existence should not be mistaken for an external cause in the Aristotelian sense. Existence is not a remote cause because it is the ontological reality of all existing entities and constitutes their existence. This causal relationship between existence and existents does not resemble the relationship between a builder and a house, in fact it is like the relationship between a speaker and speech, when the speaker is silent, there will be no speech (Sadra, 1999a).

After describing the causal relation between existence and existents, we realize that existence does not depend on its modes to exist. The notion of necessary relation between cause and effect becomes problematic and may not be applicable to the relation between existence and its modes. We say, for example, that there is no cause without an effect and no effect without having been produced by a cause. Besides, in Mulla Sadra's ontology, the causal relation between existence and existents is not a mere mental concept. It is real because existence and its modes are real and not mere logical categories. If we define a cause on the ground of bringing something into existence, existence will be fully qualified as a real cause. Hence, the modes necessarily presuppose existence. For, every individual instance becomes an existent when its real cause is associated with it. When we point out to an existent we try to assert more of than saying that it is an existent and standing in the external world, or it is a temporal being and has come into existence. We also refer indirectly to its cause or the ontological ground on which it stands, without which it becomes a non-existent. When it is stated that existence is the sole reality, we also reject the possibility of infinite causal regression and multiple realities. In Mulla Sadra's ontology, whatever exists is nothing more than the self-manifestation of the reality of existence. The causal chain begins with existence as it is the ontological fountainhead of all existents and this causal chain is finite (Sadra, 1999a).

The difference between existence and existents can also be interpreted in terms of temporality. Existence as the reality is not temporal in Aristotelian sense. If we think of existence as something temporal, it should have a beginning and an end. In this case, it presupposes a prior cause for its existence. Hence, existence remains "a-temporal" and its modes would be characterized by temporality. However, "a-temporality" of existence does not mean that existence has no time. It is true that if we accept Aristotle's definition of time, the reality of existence and temporality become contradictory. Aristotle understands time as essentially the measure of movement of the corporeal bodies, "Hence time is not movement, but only movement in so far as it admits to enumeration” (Aristotle, 1995, pp. 5-10). Time is fundamentally connected with change and movement. This analysis makes time part of the material world because change takes place in nature. By contrast, in Mulla Sadra's ontology, temporality is part of the reality of existence and the process of its self-manifestation. There 
is time because there is existence. The notion of a-temporality, then, does not refer to the existence of something beyond time. Since the notion of time is established ontologically on the reality of existence, temporality would be part of reality and it is unthinkable without it. In the meantime, this does not mean that existence is originated and, like an existent it comes into existence and ceases to be, but time becomes part of its reality.

The a-temporality that belongs to existence is a kind of time called "sarmad" or eternal time. This notion of time was employed by Mir Damad (d. 1631), Mulla Sadra's teacher in Isfahan, as developed in Kitāb al-Qabasāthaqq al-yaqīnfìthudūth al-'álam (known as al-Qabasāt). Mir Damad has classified three notions of time, each of which is related to a realm of reality. There is time that postulates the relation of the permanent to the permanent, known as "sarmad". This is the eternal time of the ontological reality, which transcends all kinds of change and movements in nature. The second type of time is related to the permanent when it initiates change. This time is called "dahr". Then, there is the relation of change to change or a temporality described as "zamān", which is time defined by Aristotle and belongs to the natural world. This is temporality with a beginning as well as an end and determines the course of natural objects in the material world (Nasr, 1966; Dabashi, 2008). All kinds of existents, which are contingent upon nothingness, pending annihilation, generated and degenerated, are temporal in terms of zamān and not sarmad. Following Mir Damad, Mulla Sadra considers existence a-temporal but not without time simply because existence is the only ontological reality. Nothing beyond or outside existence could exist or thinkable. In this sense, existence encompasses everything including time. Time is, therefore, not only the measure of movement but an essential characteristic of the self-manifestation of the reality of existence, determining every single instance of individuality.

Apparently, Mulla Sadra rejects the idea of a supra-temporal being, for whatever exists has time in one form or another. Time for existence is temporality without being affected by it or making existence temporal, because existence is not an existent. When we think of the notion of time under the influence of Aristotle's definition, we relate temporality to nature and the movement of the corporeal bodies. Mulla Sadra's interpretation of time is ontological and not naturalistic. It does not matter whether the reality is changeable or not; if it is "present", it has time. Based on this interpretation and then on the ontological difference, the presence of existence and its modes retain two kinds of temporality. The existence is eternally present has always existed and will continue to exist, whereas the modes of existence are generated and degenerated.

After establishing the ontological difference between existence and existents without going back to the metaphysical distinction between existence and essence, Mulla Sadra turns his discussion to another important principle, known as the gradation of existence (tashkik al-wujūd). This principle is central for our understanding of unity in multiplicity or identity in difference in his philosophy. Existence is one but existents are multiple. The multiplicity of existents represents the gradation of existence in various ranks pending on the intensity of existence in them. Hence, existence is the source of unity and multiplicity. What unites multiple existents and brings about their diversity is the reality of existence. Existence is one and its manifestation through its own modes generates multiplicity. This understanding of the structure of reality also resembles what Plotinus (1991) had expressed in a phrase to describe the life of the Intellectual-Principle, "to a traveller over land all is earth but earth abounding in difference: so, in this journey the life through which the Intellectual-Principle passes is one life but, in its ceaseless changing, a varied life” (p. 483). The modes of existence have also different degrees of perfection. This ontic difference among the existents is caused by the intensity of the reality in them. It is measured by their proximity to and distance from their ontological source 
(Sadra, 1999a). Since there is unity in multiplicity, the plurality of the modes of existence does not prevent us from holding that the individual instances of existence belong to a single reality. If the individual instances are not seen as the modes of existence, there would be neither ontological difference nor the real causal relation between them. There is a necessary relation of reality to the existing entities and of these entities to one another, because they belong to a single reality. This understanding of independence of the existing entities on reality of existence involves an organic unity, in which parts are determined by the whole and united by it. The unity, in this context, does not revoke multiplicity, and multiplicity does not contradict unity. These two aspects (unity and multiplicity) truly represent reality and articulate our understanding of the structure of things in the world. It should be also remembered that while existence generates multiple existents constantly, its own simplicity and perfection are not impacted by it.

\section{Conclusion}

In the conclusion, we understand that in Mulla Sadra's ontology "existence" is the sole reality constituting the concrete nature of all existing entities in the world. Whatever exists is an individual instance of existence. There is no real distinction between existence and essence in the external world. The distinction between them arises only in thinking when an existent is analysed intellectually into its universal determinations. The dichotomy of existence and essence, which has dominated Ibn Sina's metaphysics, cannot become a criterion for differentiating reality from the possible beings. A possible being is and has a concrete reality without having essence and it is a mode of existence. The distinction between reality and the possible beings in Ibn Sina's metaphysics, which is based on the essence-existence dichotomy, becomes inadequate. Instead the distinction between existence and its modes is established on an existentialist-monistic ontology, which asserts the simplicity of existence on one side and the diversity of its individual instances on the other. Each of these individual instances has a unity in the sense that it does not suffer the division between existence and essence in its nature. It is also different from its source in terms of the degrees of intensity, causality, and temporality.

\section{References}

Aristotle. (1995). Metaphysics. In J. Barnes (Ed.), Complete works of Aristotle. Princeton, New Jersey: Princeton University Press.

Dabashi, H. (2008). Mir Damad and the founding of the school of Isfahan. In S. H. Nasr and O. Leaman (Eds.), History of Islamic philosophy (p. 611). London and New York: Routledge.

Nasr, S. H. (1966). The school of Isfahan. In M. M. Sharif (Ed.), A history of Muslim philosophy (Vol. 2, pp. 915-917). Wiesbaden: Otto Harrassowitz.

Plotinus. (1991). The Enneads. London: Penguin Books.

Sabzawari, M. H. (1977). The metaphysics of Sabzawari. New York: Caravan Books.

Sadra, M. (1981). Al-Shawāhid al-rubuiyyah. Tehran: University Publication Centre.

Sadra, M. (1999a). Al-Asfār al-Arba'a. Beirut: Dar Ihya’ al-Turath al-‘Arabi.

Sadra, M. (1999b). Al-Mazāhīr al-Ilāhiyyah (Book of divine manifestation concerning the secrets of the sciences that lead to perfection). Teheran: Sadra Islamic Philosophy Research Institute (SIPRIn) Publication.

Sadra, M. (2014). al-Mashā‘ir (The book of metaphysical penetration). Provo, Utah: Brigham Young University Press.

Sina, I. (2005). Kitāb al-Shifā (The metaphysics of the healing). Provo, Utah: Brigham University Press.

Suárez, F. (1983). On the essence of finite being as such, on the existence of that essence and their distinction. Milwaukee and Wisconsin: Marquette University Press.

Suhrawardi, S. A. (1999). Hikmat al-Ishrāq (The philosophy of illumination). Provo, Utah: Brigham Young University Press. 